\title{
THE ROLE OF NRAMP1/SLC11A1 GENE VARIANT D543N (1730G/A) IN THE GENETIC SUSCEPTIBILITY TO DEVELOP RHEUMATOID ARTHRITIS IN THE MEXICAN MESTIZO POPULATION
}

\author{
Perla Niño-Moreno ${ }^{1,2}$, Edgar Turrubiartes-Martínez ${ }^{1}$, Brenda Oceguera-Maldonado ${ }^{1}$, \\ Nubia Baltazar-Benítez ${ }^{1}$, Cindy Negrete-GonzÁlez ${ }^{1}$, Brenda Oliva-Ramírez ${ }^{1}$, Lourdes Baranda ${ }^{2,3,4}$ \\ AND ROBERTO GONZÁLEZ-AMARO ${ }^{2,3 *}$ \\ ${ }^{1}$ Laboratory of Genetics and Molecular Diagnostics, Faculty of Chemical Sciences, Universidad Autónoma \\ de San Luis Potosí; ${ }^{2}$ Research Center for Health Sciences and Biomedicine, Universidad Autónoma de San Luis Potosí; \\ ${ }^{3}$ Department of Immunology, Faculty of Medicine, Universidad Autónoma de San Luis Potosí; ${ }^{4}$ Regional Unit \\ of Rheumatology and Osteoporosis, Hospital Central Dr. Ignacio Morones Prieto. San Luis Potosí, S.L.P., Mexico
}

\begin{abstract}
Background: Rheumatoid arthritis is a chronic inflammatory disease whose cause has not been fully elucidated. However, genetic factors seem to have an important role in its pathogenesis. Objective: We analyzed the possible association between rheumatoid arthritis and variants of the SLC11A1 gene, which encodes for NRAMP1, a protein involved in the activation of phagocytes and synthesis of proinflammatory cytokines. Methods: In a case-control study in a Mexican Mestizo population, blood samples from 188 patients with rheumatoid arthritis and 133 healthy individuals were obtained to determine the frequency of SLC11A1 gene variants INT4 (469+14G/C or rs3731865), D543N (1730G/A or rs17235409) and 3'UTR $(1729+55$ del 4 or $r s 17235416)$ by polymerase chain reaction and restriction fragment length polymorphism. Results: We found similar frequencies of INT4 and 3'UTR polymorphisms in patients and controls ( $p=0.18$ and 0.89 , respectively). In contrast, a significantly lower frequency of the D543N polymorphism was observed in patients with rheumatoid arthritis compared to controls ( $p$ corrected $=0.016 ;$ OR: $0.48 ; 95 \% \mathrm{Cl}: 0.28-0.80$ ). Conclusion: Our data suggest that the D543N variant of SLC11A1 gene has a protective effect in the development of rheumatoid arthritis, an interesting finding that has not been previously reported in any population. (REV INVES CLIN. 2017;69:5-10)
\end{abstract}

Key words: Rheumatoid arthritis. Phagocyte. SLC11A1 gene variant.

Corresponding author:

*Roberto González-Amaro

Department of Immunology

Faculty of Medicine, UASLP

Ave. V. Carranza, 2405

C.P. 78210, San Luis Potosí, S.L.P., México

E-mail: rgonzale@uaslp.mx

Received for publication: 20-01-2017

Accepted for publication: 07-02-2017 


\section{INTRODUCTION}

Rheumatoid arthritis (RA) is an immune-mediated disease characterized by chronic inflammation of diarthrodial joints with synovial hyperplasia, progressive destruction of cartilage, and juxta-articular bone resorption, which may seriously affect the quality of life and survival of these patients ${ }^{1}$. Although the cause of RA has not been fully elucidated, different studies have indicated that genetic factors may account for approximately $50-65 \%$ of the risk in the development of $\mathrm{RA}^{1,2}$.

Natural resistance-associated macrophage proteins (NRAMP) 1 and 2 are transmembrane molecules classified as solute carriers that mediate the uptake of divalent cations such as ferrous iron $\left(\mathrm{Fe}^{2+}\right)$ and manganese $\left(\mathrm{Mn}^{2+}\right)^{3,4}$. In humans, NRAMP1 is encoded by the SLC11A1 gene, which is $14 \mathrm{~kb}$ in length with 15 exons and is located on chromosome 2 q35 3,4. NRAMP 1 is expressed by monocytes, macrophages, and polymorphonuclear neutrophils, and has an important role in the control of replication of intracellular parasites by altering the intravacuolar environment of the microbe-containing phagolysosome ${ }^{4,5}$. In addition, NRAMP1 seems to be involved in the priming and activation of phagocytes, participating in the induction of synthesis of proinflammatory cytokines (tumor necrosis factor-a, interleukin-1) and nitric oxide as well as in the expression of class II major histocompatibility complex (MHC) molecules ${ }^{5-8}$. Therefore, it is very feasible that NRAMP1 may have a relevant role in the pathogenesis of inflammatory and autoimmune diseases. Accordingly, different studies have analyzed the possible association between variants of the SLC11A1 gene and autoimmunity 9 .

At least 17 genetic variants of SLC11A1 gene have been described and 10 of these have been characterized in depth ${ }^{9-11}$. Nine of these variants are single nucleotide polymorphisms (SNP) and the other one corresponds to a microsatellite GTn-repeat polymorphism of the promoter region ${ }^{9-11}$. Among these variants, it has been described that the INT4 SNP $(469+14 G / C$ or rs3731865) is located at exon $4 a$, generates a termination codon into exon 5 , and affects the expression and function of NRAMP1. Likewise, the D543N SNP (1730G/A or rs17235409) generates a missense mutation in codon 543 (aspartic acid to asparagine in exon 15 ) that could affect the function of the protein. Moreover, the 3'UTR $(1729+55$ del 4 or rs17235416) variant corresponds to a 4 bp insertion/deletion immediately 3 ' of the stop codon; however, the possible effect of this variant on the expression and function of NRAMP1 has not been defined yet.

Different studies have analyzed the possible association between genetic variants of SLC11A1 and infectious or autoimmune inflammatory diseases. Thus, a significant association has been detected between several SLC11A1 polymorphisms (mainly the GTn promoter alleles 2 and 3 or rs534448891) and infectious diseases, mostly tuberculosis $9,10,12,13$. Moreover, a significant positive association between the $469+14 \mathrm{G} / \mathrm{C}$ (rs3731865) SNP and autoimmune diseases, including RA, has been detected ${ }^{9}$. In contrast, the $237 \mathrm{C} / \mathrm{T}$ SNP (rs7573065) seems to exert a protective effect in the development of inflammatory bowel disease ${ }^{9,14}$. However, most of these studies have been performed in Asian and Caucasian populations, and the possible association between SLC11A1 gene variants and RA has not been previously analyzed in the Mexican Mestizo population, which comprises almost one hundred million individuals. Therefore, we decided to assess the frequency of the INT4 SNP $(469+14 \mathrm{G} / \mathrm{C}$ or rs3731865), D543N SNP (1730G/A or rs17235409) and 3'UTR (1729+55del4 or rs17235416) SLC11A1 gene variants in patients with RA and healthy controls. This study indicates that there is an interesting and significant negative association between the D543N SNP and RA.

\section{MATERIAL AND METHODS}

\section{Subjects}

The state of San Luis Potosí, in central Mexico, has an extension of $61,000 \mathrm{~km}^{2}$ with approximately 2.5 million inhabitants, mostly Mestizo population. However, in the western region of the state a significant fraction of the population corresponds to native Amerindians, which represents approximately $12 \%$ of the inhabitants of the state. The city of San Luis Potosí is located in this region and is mainly inhabited by Mexican Mestizos. We studied 321 unrelated Mexican Mestizo individuals from the city of San Luis Potosí; of them, 188 had RA, according to the classification criteria of the American College of Rheumatology ${ }^{15}$. 
Figure 1. Identification of the SLC11A1 gene variants INT4 (rs3731865), D543N (rs17235409) and 3'UTR (rs17235416) by polymerase chain reaction plus restriction fragment length polymorphism. In the upper panel, the primers, restriction enzymes and length of amplicon fragments are indicated. In the lower panel two examples of genotype identification are shown, for INT4 (lane 1, ladder; lane 2, allele C; lane 3, allele G) and 3'UTR variants (lane 1, allele ND; lanes 2 and 3, allele D).

\begin{tabular}{llcl}
\hline Polymorphisms & \multicolumn{1}{c}{ Primers (5' to 3') } & $\begin{array}{c}\text { Restriction } \\
\text { enzyme }\end{array}$ & $\begin{array}{c}\text { Restriction fragment } \\
\text { size (bp) }\end{array}$ \\
\hline rs3731865 & TCTCTGGCTGAAGGCTCTCC & Apa I & (G) 624 \\
$\begin{array}{l}\text { (INT4) } \\
\text { rs17235409 }\end{array}$ & TGTGCTATCAGTTGAGCCTC & (C) 455,169 \\
$\begin{array}{l}\text { (D543N) } \\
\text { rs } 17235416\end{array}$ & AACATCTCCCCAATTCATGGT & Ava II & (G) $126,79,39$ \\
(3'UTR) & GCATCTCCCCACTCTATCCTG & & (A) 201,39 \\
\hline
\end{tabular}

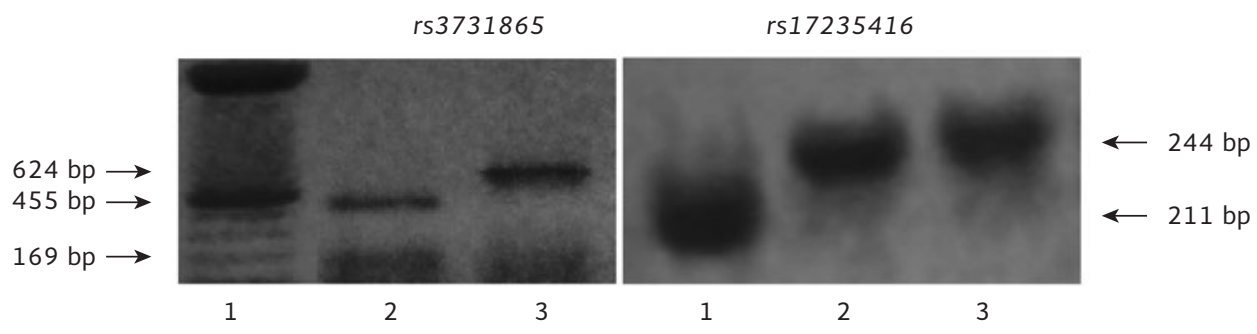

Patients were recruited at the Regional Center of Rheumatology and Osteoporosis in the Hospital Central "Dr. Ignacio Morones Prieto", San Luis Potosí; 20 were male and 168 were female, with an age range of 17-60 years (arithmetic mean: 47.4 years). Disease duration ranged between one and 37 years and almost all of the patients were receiving disease-modifying anti-rheumatic drugs. Most patients had shown a moderate or good response to therapy at the time of study. Patients with HIV infection, diabetes mellitus, or another inflammatory/autoimmune disease were not included in the study. As controls, $133 \mathrm{~h}$ althy individuals (25 male, 108 female; age range 2050 years, with an arithmetic mean of 44.2 years) were included. All study subjects signed an informed consent; the study was approved by the institutional Bioethics Committee. Peripheral blood samples were obtained from all participants.

\section{Blood samples and genomic DNA isolation}

Genomic DNA was extracted from peripheral blood samples by using the Wizard ${ }^{\circledR}$ Genomic DNA Purification kit (Promega, Madison, WI, USA), and the DNA was dissolved in sterile distilled water. Quantity and purity were determined with an Optizen Pop spectrophotometer (Mecasys Co, Daejeon, Korea).

\section{Detection of SLC11A1 gene polymorphisms}

The SLC11A1 variants INT4 SNP $(469+14 \mathrm{G} / \mathrm{C}$ or rs3731865), D543N SNP (1730G/A or rs17235409) and 3'UTR (1729+55del4 or rs17235416) were determined by polymerase chain reaction (PCR) plus restriction fragment length polymorphism (RFLP). The PCRs were performed in a total volume of $50 \mu \mathrm{l}$ of a solution containing $100 \mathrm{ng}$ genomic DNA, $5 \mu \mathrm{l}$ free $\mathrm{Mg}^{2+} 10 \mathrm{X}$ buffer (Invitrogen Life Technologies, Carlsbad, CA, USA), $200 \mu \mathrm{M}$ dNTPs, $2 \mathrm{mM} \mathrm{MgCl}_{2}$ and $1 \mathrm{U}$ of recombinant Taq DNA polymerase (Invitrogen). Thermal cycling was performed on a TC-412 device (Techne, Cambridge, UK). Cycling conditions for the variants D543N (rs17235409) and 3'UTR (rs17235416) were: $94^{\circ} \mathrm{C}$ for 10 minutes, 35 cycles of $94^{\circ} \mathrm{C}$ for $30 \mathrm{sec}$ onds, $68^{\circ} \mathrm{C}$ for 30 seconds, and $72^{\circ} \mathrm{C}$ for 30 seconds, with a final five-minute extension at $72^{\circ} \mathrm{C}$. In the case of INT4 (rs3731865) cycling conditions were $94^{\circ} \mathrm{C}$ for 10 minutes, 40 cycles of $94^{\circ} \mathrm{C}$ for 30 seconds, $60^{\circ} \mathrm{C}$ for 30 seconds, and $72^{\circ} \mathrm{C}$ for 30 seconds, with a final five-minute extension at $72^{\circ} \mathrm{C}$. Primers employed for each $\mathrm{PCR}$ are shown in figure 1 . Amplicons were digested at $37^{\circ} \mathrm{C}$ for 24 hours with the proper restriction enzyme (Amersham Pharmacia Biotech, Piscataway, NJ) (Table 1 ) in a $20 \mu$ l reaction mix containing $1 \mathrm{X}$ restriction enzyme buffer and bovine 
Table 1. Distribution of SLC11A1 polymorphisms in patients with rheumatoid arthritis and controls

\begin{tabular}{|c|c|c|c|c|}
\hline Polymorphism & $\begin{array}{c}\text { Patients } \\
\text { n (\%) }\end{array}$ & $\begin{array}{c}\text { Controls } \\
\text { n (\%) }\end{array}$ & $\begin{array}{c}p \\
\text { value }\end{array}$ & OR $(95 \% \mathrm{Cl})$ \\
\hline \multicolumn{5}{|l|}{$r s 3731865$} \\
\hline $\mathrm{G} / \mathrm{G}$ & $125(66.5)$ & $72(59.1)$ & 0.186 & $1.37(0.86-2.2)$ \\
\hline $\mathrm{G} / \mathrm{C}$ and $\mathrm{C} / \mathrm{C}$ & $63(33.5)$ & $50(40.9)$ & & \\
\hline \multicolumn{5}{|l|}{ rs17235409 } \\
\hline $\mathrm{G} / \mathrm{G}$ & $139(76.4)$ & $67(60.9)$ & $0.016^{*}$ & $0.48(0.28-0.80)$ \\
\hline $\mathrm{G} / \mathrm{A}$ and $\mathrm{A} / \mathrm{A}$ & $63(23.6)$ & $43(39.1)$ & & \\
\hline \multicolumn{5}{|l|}{ rs17235416 } \\
\hline ND/ND & $67(48.5)$ & $50(50.0)$ & 0.895 & $0.94(0.56-1.57)$ \\
\hline ND/D and D/D & $71(51.5)$ & $50(50.0)$ & & \\
\hline
\end{tabular}

${ }^{*}$ Corrected $p$ value (uncorrected $=0.0056$ ).

$\mathrm{Cl}$ : confidence interval; D: deletion; ND: non-deletion; OR: odds ratio.

serum albumin (BSA). Digested products were run on $2 \%$ agarose gels, which were stained with ethidium bromide and visualized using a UV transilluminator.

\section{Statistical analysis}

Frequencies of genotypes were determined by direct counting, and genotype distribution and Hardy-Weinberg equilibrium were tested by using the Arlequin software version 3.11 (University of Bern, Switzerland). The statistical significance of genotype frequency differences between patients and controls was determined by Fisher's exact test using $2 \times 2$ contingency tables and GraphPad software (San Diego, $C A$ ). Corrected $p$ values were obtained by multiplying raw values by the total number of variables analyzed and were considered significant when they were $<0.05$.

\section{RESULTS}

The SLC11A1 variants INT4 (rs3731865), D543N (rs17235409), and 3'UTR (rs17235416) were determined by PCR-RFLP by using the Apa I, Ava II and Fok I restriction enzymes, respectively (Fig. 1). In all cases, the alleles were in Hardy-Weinberg equilibrium.

As shown in table 1 , the frequency of the INT4 (rs3731865) SNP was not significantly different ( $p=0.18$, OR: $1.37 ; 95 \% \mathrm{Cl}: 0.86-2.20$ ) in patients with RA (33.5\%) and healthy controls (40.9\%). Likewise, when the genotype distribution of the 3'UTR (rs17235416) variant was analyzed, we found a very similar frequency in patients with RA (51.4\%) and healthy controls $(50.0 \%)(p=0.89$; OR: $0.94 ; 95 \%$ $\mathrm{Cl}$ : 0.56-1.57). In contrast, we observed a significantly lower frequency of the D543N (rs17235409) SNP in patients with RA (23.6\%) compared to healthy controls $(39.1 \%)$ ( $p$ uncorrected $=0.0056$, $p$ corrected $=0.016$; OR: $0.48 ; 95 \% \mathrm{Cl}: 0.28-0.80$ ).

\section{DISCUSSION}

Although different factors have been involved in the etiology and pathogenesis of RA, it is evident that the cause and mechanisms of tissue damage in this disorder remain as very relevant points to be fully elucidated ${ }^{1}$. Genetic factors have been found to significantly contribute to the risk for $\mathrm{RA}^{1,2}$. Thus, some MHC alleles, as well as different variants of immune genes, show a significant association with this condition$^{2}$. Accordingly, different studies have addressed the possible role of $\mathrm{MHC}$ and other gene alleles in the susceptibility and severity of RA in Mexicans ${ }^{16,17}$.

The SLC11A1 gene encodes for a transmembrane protein (NRAMP1) that is mainly expressed by professional phagocytes (monocytes, macrophages, neutrophils $)^{5}$. NRAMP1 mediates the uptake of divalent cations in phagolysosomes and is involved in the activation and effector mechanisms of phagocytes, including their bactericidal activity and the synthesis of proinflammatory cytokines and nitric oxide ${ }^{5-7}$. Thus, it is very feasible that SLC11A1/NRAMP1 may be involved in the pathogenesis of chronic inflammatory conditions, including $\mathrm{RA}^{8}$. Accordingly, in the last 10 years, several studies on the association of SLC11A1 variants and RA in different populations 
have been published ${ }^{10,18-21}$. In addition, a possible association between a SLC11A1 promoter polymorphism and RA severity ${ }^{22}$, or risk for idiopathic arthritis or juvenile rheumatoid arthritis, has been reported ${ }^{23,24}$. However, in a recent meta-analysis performed by $\mathrm{Ar}-$ cher, et al. ${ }^{9}$, only a single significant association was detected between SLC11A1 variants and RA, namely the INT4 SNP $(469+14 \mathrm{G} / \mathrm{C}$ or rs3731865), with an OR: 1.60 ( $95 \% \mathrm{Cl}: 1.20-2.13$ ). Based on these data, we decided to analyze the possible association between three variants of SLC11A1 gene and RA in the Mexican Mestizo population.

In contrast with previous reports ${ }^{9}$, we observed a similar frequency of the INT4 (rs3731865) SNP in RA patients and controls. Likewise, no significant association was detected between the 3'UTR ( $r$ 17235416) variant of SLC11A1 gene and RA. However, we observed a significantly lower frequency of the D543N (rs17235409) SNP in RA patients compared to controls ( $p$ corrected $=0.016$ : OR: $0.48 ; 95 \% \mathrm{Cl}: 0.28-$ 0.80 ). Since this SNP generates a missense mutation in codon 543, which results in the substitution of negatively charged aspartic acid by uncharged asparagine, it would be expected that this variant affects the function of the protein. However, this point has not been fully addressed and no data are available regarding the precise effect of this amino acid substitution on the levels of expression or the function of NRAMP1. In any case, this is the first report of a negative association between the D543N (rs17235409) SNP and RA. In this regard, a study by Singal, et al. suggested a possible protective effect of D543N variant in the development of RA (relative risk $=0.06$; uncorrected $p=0.014$ ); however, the value of $p$ corrected in this study was not significant ${ }^{21}$. Moreover, it has been reported that the D543N SNP apparently confers protection against Mycobacterium tuberculosis reactivation in Cambodian patients infected with HIV $(p=0.04 ; \text { OR: } 0.21)^{25}$, an association that was not observed in Indian patients ${ }^{23}$. All these data suggest that the D543N SLC11A1 variant has a complex role in the susceptibility to inflammatory and infectious disease, with a relevant interaction with the genetic background of individuals studied ${ }^{26}$.

It has been proposed that the high mortality by M. tuberculosis infection observed over the past three centuries has exerted an important selective force, increasing the frequency of allelic gene variants (including those of the SLC11A1 gene) that enhance the resistance to this pathogen ${ }^{27}$. Since these allelic variants are associated with an increased capability to generate proinflammatory mediators by immune cells, it has been hypothesized that the selective force generated by $M$. tuberculosis in humans has resulted in an increased susceptibility to chronic inflammatory conditions, including $\mathrm{RA}^{27}$. In this regard, our previous report on the lack of association between the D543N SNP and tuberculosis in Mexican Mestizos ${ }^{28}$ is of interest.

In summary, we have identified a variant (D543N or 1730G/A, rs17235409) of an immune gene (SLC11A1/ NRAMP1), which has an important role in the activation and effector functions of professional phagocytes and that apparently confers protection in the development of RA in the Mexican Mestizo population. We consider that it would be of interest to confirm this finding in a larger study, as well as to explore the possible effect of this SNP on the expression and function of NRAMP1 and its impact on the pathogenesis of RA.

\section{ACKNOWLEDGMENTS}

This study was finantially supported by the Department of Immunology, Faculty of Medicine, UASLP, San Luis Potosí, SLP, Mexico.

\section{REFERENCES}

1. Smolen JS, Aletaha D, Mclnnes IB. Rheumatoid arthritis. Lancet. 2016;388:2023-38

2. Okada Y, Wu D, Trynka G, et al. Genetics of rheumatoid arthritis contributes to biology and drug discovery. Nature. 2013; 506:376-81.

3. Cellier M, Govoni G, Vidal S, et al. Human natural resistanceassociated macrophage protein: cDNA cloning, chromosomal mapping, genomic organization, and tissue-specific expression. J Exp Med. 1994:180:1741-52.

4. Cellier M. Nramp. From sequence to structure and mechanism of divalent metal import. Curr Top Memb. 2012;69:249-93.

5. Cellier M. Cell-type specific determinants of NRAMP1 expression in professional phagocytes. Biology. 2013;2:233-83.

6. Blackwell JM, Searle S, Goswami T, Miller EN. Understanding the multiple functions of Nramp1. Microbes Infect. 2000;2:317-21.

7. Blackwell JM, Searle S. Genetic regulation of macrophage activation: understanding the function of Nramp1 (=Ity/Lsh/Bcg). Immunol Lett. 1999;65:73-80.

8. Peters LC, Jensen JR, Borrego A, et al. Slc1 1a1 (formerly NRAMP1) gene modulates both acute inflammatory reactions and pristane-induced arthritis in mice. Genes Immun. 2007;8:51-6.

9. Archer NS, Nassif NT, O'Brien BA. Genetic variants of SLC11A1 are associated with both autoimmune and infectious diseases: systematic review and meta-analysis. Genes Immun. 2015;16: 275-83

10. Ates O, Dalyan L, Musellim B, et al. NRAMP1 (SLC11A1) gene polymorphisms that correlate with autoimmune versus infectious 
disease susceptibility in tuberculosis and rheumatoid arthritis. Int J Immunogen. 2008;36:15-19.

11. Buu N, Sánchez F, Schurr E. The BCG host-resistance gene. Clin Infect Dis. 2000;31(Suppl 3):S81-5.

12. Ryu S, Park YK, Bai GH, Kim SJ, Park SN, Kang S. 3'UTR polymorphisms in the NRAMP1 gene are associated with susceptibility to tuberculosis in Koreans. Int J Tuberc Lung Dis. 2000;4:577-80.

13. Blackwell JM. Structure and function of the natural-resistance associated macrophage protein (Nramp1), a candidate protein for infectious and autoimmune disease susceptibility. Mol Med Today. 1996:2:205-11.

14. Sun M, Zhang L, Shi S. Associations between NRAMP1 polymorphisms and susceptibility to ulcerative colitis/Crohn's disease: A Meta-Analysis. Immunol Invest. 2016;45:255-70.

15. Aletaha D, Neogi T, Silman A, et al. 2010 Rheumatoid Arthritis Classification Criteria: an American College of Rheumatology/ European League Against Rheumatism collaborative initiative. Ann Rheum Dis. 2010;69:1580-8.

16. Rodríguez-Carreón AA, Zúñiga J, Hernández-Pacheco G, et al. Tumor necrosis factor-alpha-308 promoter polymorphism contributes independently to HLA alleles in the severity of rheumatoid arthritis in Mexicans. J Autoimmun. 2005;24:63-8.

17. Ruiz-Morales JA, Vargas-Alarcón G, Flores-Villanueva PO, et al. HLA-DRB1 alleles encoding the "shared epitope" are associated with susceptibility to developing rheumatoid arthritis whereas HLA-DRB1 alleles encoding an aspartic acid at position 70 of the beta-chain are protective in Mexican Mestizos. Hum Immunol. 2004:65:262-9

18. Yen $\mathrm{JH}$, Lin $\mathrm{CH}$, Tsai WC, et al. Natural resistance-associated macrophage protein 1 gene polymorphisms in rheumatoid arthritis. Immunol Lett. 2006;102:91-7.

19. Yang YS, Kım SJ, Kım JW, Koh EM. NRAMP1 gene polymorphisms in patients with rheumatoid arthritis in Koreans. J Korean Med Sci. 2000;15:83-7.
20. Shaw MA, Clayton D, Atkinson SE, et al Linkage of rheumatoid arthritis to the candidate gene NRAMP1 on 2 q35. J Med Genet. 1996;33:672-7.

21. Singal DP, Li J, Zhu Y, Zhang Y. NRAMP1 gene polymorphisms in patients with rheumatoid arthritis. Tissue Antigens. 2000;55: 44-7

22. Rodríguez MR, González-Escribano MF, Aguilar F, Valenzuela A García A, Núñez-Roldán A. Association of NRAMP1 promoter gene polymorphism with the susceptibility and radiological severity of rheumatoid arthritis. Tissue Antigens. 2002;59: 311-5.

23. Runstadler JA, Säilä $H$, Savolainen A, et al. Association of SLC11A1 (NRAMP1) with persistent oligoarticular and polyarticular rheumatoid factor-negative juvenile idiopathic arthritis in Finnish patients: haplotype analysis in Finnish families. Arthritis Rheum. 2005;52:247-56.

24. Chen YJ, Li RN, Lin CH, Yen JH. The role of monocytes and SLC11A1 polymorphisms in the pathogenesis of Chlamydia-induced reactive arthritis. Scand J Rheumatol. 2013;42:146-9.

25. Affandi JS, Kumar M, Agarwal U, Singh S, Price P. The search for a genetic factor associating with immune restoration disease in HIV patients co-infected with Mycobacterium tuberculosis. Dis Markers. 2013;34:445-9.

26. De Franco M, Peters LC, Correa MA, et al. Pristane-induced arthritis loci interact with the Slc11a1 gene to determine susceptibility in mice selected for high inflammation. PLoS One. 2014; 9:e88302.

27. Mobley JL. Is rheumatoid arthritis a consequence of natura selection for enhanced tuberculosis resistance? Med Hypotheses. 2004;62:839-43.

28. Niño-Moreno P, Portales-Pérez D, Hernández-Castro $B$, et al. P2X7 and NRAMP1/SLC11 A1 gene polymorphisms in Mexican Mestizo patients with pulmonary tuberculosis. Clin Exp Immunol. 2007;148:469-77. 